\title{
BMJ Open Cross-sectional survey to describe medicine use among Syrian asylum seekers and refugees in a German federal state: looking beyond infectious diseases
}

\author{
Saleh Aljadeeah (D) , ${ }^{1}$ Veronika J Wirtz, ${ }^{2}$ Eckhard Nagel ${ }^{1}$
}

To cite: Aljadeeah S, Wirtz VJ, Nagel E. Cross-sectional survey to describe medicine use among Syrian asylum seekers and refugees in a German federal state: looking beyond infectious diseases. BMJ Open 2021;11:e053044. doi:10.1136/ bmjopen-2021-053044

- Prepublication history and additional supplemental material for this paper are available online. To view these files, please visit the journal online (http://dx.doi.org/10.1136/ bmjopen-2021-053044)

Received 03 May 2021 Accepted 10 September 2021

Check for updates

(c) Author(s) (or their employer(s)) 2021. Re-use permitted under CC BY-NC. No commercial re-use. See rights and permissions. Published by BMJ.

${ }^{1}$ Institute of Medical

Management and Health

Science, University of Bayreuth, Bayreuth, Germany

${ }^{2}$ Department of Global Health,

Boston University School

of Public Health, Boston,

Massachusetts, USA

Correspondence to Dr Saleh Aljadeeah; saleh.aljadeeah@uni-bayreuth. de

\section{ABSTRACT}

Objectives The aim of our study was to describe medicine use and document self-reported diseases or conditions for which medicines were used among Syrian asylum seekers and refugees (AS\&Rs) in the German state of North Rhine-Westphalia (NRW). We examined in this study differences in the use of medicines among different age and sex groups of the study participants.

Setting Fifteen different refugee shared accommodation centres in the greater Cologne area, a community centre with a language school and consultation office, and other places frequented by the Syrian community.

Participants Syrian AS\&Rs registered in NRW and residing in the city of Cologne or surrounding areas.

Primary outcome measures The prevalence of using at least one medicine in the 7 days preceding data collection, and the use of prescribed medicines and self-medication. Results Of the 1641 Syrian AS\&Rs who took part in our study, the overall 7-day prevalence of medicine use was $34.9 \%$. Among adults, headache and hypertension were the most common indications that led to medicine use. By dose, hypertension (954 doses) and diabetes (595 doses) were the first and second most frequent indication. Among children, fever and cough were the most common indication; ibuprofen and hederae helicis folium preparations were the most used medicines. Low prevalence was found of medicine use for the treatment of either infectious diseases or mental disorders.

Conclusion Among the Syrian AS\&Rs in NRW who participated in the study, non-communicable diseases (NCDs) were common presumed causes of use of medication among adults. We encourage future studies to pay more attention to NCDs medicine use among AS\&Rs. Researchers should also consider reaching AS\&Rs who live in private housing and not limit studies only to newly arrived AS\&Rs who live in shared accommodation centres.

\section{INTRODUCTION}

The profile of countries affected by conflicts has been gradually shifting, resulting in increasing displacement of populations with higher incomes and life expectancies. ${ }^{1}$ Correspondingly, there has been a shift in the burden

\section{Strengths and limitations of this study}

- This is the first study to report comprehensively on medicine use, including prescription and selfmedication, and indications among a group of asylum seekers and refugees in Germany.

- To increase generalisability of this study, we employed a combination of sampling methods and took into account key demographic variables (age and sex).

- The target population was involved in several stages of the research design and implementation. This has ensured that the study instruments were well adapted to the culture of the target population.

- The study was restricted to medicines used over the previous 7 days in order to maximise the participants' recall accuracy. However, using a limited time frame could have led to underestimating the use of medicines.

- A limitation of this study is related to the seasonal variation of medicine use. The study lasted for 6 months (July-December) capturing part of the seasonal variation expected annually.

of disease among displaced populations from infectious to chronic diseases. ${ }^{12}$ Studies have reported that non-communicable diseases (NCDs) were the most common health problems among asylum seekers and refugees (AS\&Rs) in several countries. ${ }^{23}$ More generally, 7 of the 10 leading causes of deaths in 2019 globally were NCDs. ${ }^{4}$ In contrast to acute infectious diseases, pharmacotherapy for chronic diseases typically entails continuous expenditures and patient retention in lifelong care. ${ }^{5}$ Care for some NCDs involves high costs, including expensive medications and frequent laboratory tests. ${ }^{6}$ Disruptions and shortages of medicines pose a challenge for the NCDs care among AS\&Rs in many countries. ${ }^{78}$ 
Germany has received a large number of AS\&Rs over the past decade. To date, research on the health status and medical care of AS\&Rs in Germany largely focuses on mental disorders and infectious diseases. Bozorgmehr et al identified 52 articles in a systematic review covering 25 years of publications on AS\&Rs health; of these, 30 focused on mental diseases, 12 on infectious diseases and 6 on access to healthcare services and mental diseases among children. One of the remaining four studies was a systematic review which also focused on mental diseases, while the other three studies covered various topics including access to healthcare services, mental diseases, infectious diseases and NCDs. ${ }^{9}$ The lack of research about NCDs among AS\&Rs diverges from calls for better evidence about the burden of NCDs and interventions to tackle them in this population. ${ }^{1210}$

Articles 4 and 6 of the asylum seekers benefit act (Asylbewerberleistungsgesetz) restrict the access to healthcare services among asylum seekers in Germany to emergency medical care, treatment for acute and painful conditions, care during pregnancy and childbirth, vaccinations and other 'necessary preventive measures'. Asylum seekers can obtain regular access to healthcare through standard statutory health insurance once they receive refugee status. In addition to the system-related restrictions, AS\&Rs face other obstacles when accessing healthcare services. According to a previous study that has explored the barriers to accessing medicines among Syrian AS\&Rs, language barriers and the possibility of purchasing medicines without a prescription were the most common barriers. $^{11}$

Use of medicines is the most common intervention in healthcare. Medicines constitute an important part of disease prevention, treatment and management. ${ }^{12}$ Previous studies have documented inequalities in healthcare utilisation, including medication use in comparisons between migrants and natives in Germany. ${ }^{13}$ Little is currently known about the use of medicines among AS\&Rs in Germany. Kahl and Kühlein published two studies on prescription data among a sample of asylum seekers in one reception centre in Erlangen, Bavaria. ${ }^{14} 15$ One of these studies focused on antibiotics and the other on psychotropic medicines. Another study investigated healthcare utilisation, including medicines use, among asylum seekers in Halle, Saxony-Anhalt. ${ }^{16}$ These three studies were limited to prescribed medicines and none provided adequate information on the use of medicines for chronic NCDs. All medicines, including those used by self-medication, should be considered when estimating medicine use rates in a given population. ${ }^{17}$ There is an urgent need for studies that comprehensively describe the use of medicines-including all therapeutic classesamong AS\&Rs for the prevention and treatment of various diseases, including NCDs. ${ }^{10}$

The overall aim of this study was to provide an understanding of medicines use and document self-reported disease or conditions for which medicines were used among Syrian AS\&Rs registered in North Rhine-Westphalia
(NRW), Germany. This also includes describing the prevalence and patterns of medicine use and examine any differences in the use of medicines among different age and sex groups of the study participants.

\section{METHODS}

\section{Study design and sample}

The study took place in the state of NRW, Germany, between July and December 2019. This study was based on a cross-sectional survey. We were unable to obtain access to the disaggregated NRW census data of AS\&R as our sample frame, and therefore, used quota sampling, in conjunction with convenience and snowball sampling; this is a common approach for studies with AS\&R. ${ }^{18}$ We used multiple entry points into the Syrian AS\&R community to reduce selection bias that could have resulted from snowball sampling. For the quota sampling, we divided the study population into strata according to age and sex. The fraction of each stratum was estimated using census data from the statistics office of NRW, which provided aggregated data on the age and sex distribution of Syrian AS\&Rs in NRW. Further details regarding the study design, sampling methods and the participants are described in Aljadeeah et al. ${ }^{11}$ Syrian AS\&Rs of all ages who had their addresses registered in the state of NRW were eligible. The term asylum seeker included those who applied for asylum in Germany and their asylum application hasn't been approved yet or has been rejected. The term refugee included those whose asylum applications in Germany had been approved by the BAMF and those who were allowed to stay in Germany due to a ban on deportation.

\section{Data collection}

As described in Aljadeeah et al, ${ }^{11}$ one researcher (SA) recruited participants from fifteen different refugee shared accommodation centres (RSACs) in the greater Cologne area, at a community centre with a language school and consultation office, and at other places frequented by the Syrian community, including Syrian restaurants and cafes, and during social events for the Syrian community.

A questionnaire (that was primarily composed of validated instruments and questions used in other studies) was used to collect data. ${ }^{192}$ Information about the use of medicines was collected using questions from the German Health Interview and Examination Survey for Adults (DEGS) ${ }^{19}$ and the German Health Interview and Examination Survey for Children and Adolescents (KiGGS) ${ }^{20}$ The DEGS and KiGGS are national representative surveys that the Robert Koch Institute, the leading national health institute in Germany, has regularly conducted since 2008 and 2003. The DEGS and KiGGS aim to collect data on the health and health determinants, including medicines use, of the adult and children and adolescents in a representative sample of the general population in Germany. ${ }^{19} 20$ The DEGS and KiGGS survey instruments 
Table 1 Seven-day prevalence of the use of at least one medicine, by user sex and age

\begin{tabular}{|c|c|c|c|c|}
\hline & \multicolumn{2}{|c|}{$\begin{array}{l}\text { 7-day prevalence } \\
\text { of medicines use }\end{array}$} \\
\hline & & & $\mathbf{n}$ & $\begin{array}{l}\text { Proportion } \\
\text { of total (\%) }\end{array}$ \\
\hline \multicolumn{2}{|c|}{ Total $(n=1641)$} & & 573 & 34.9 \\
\hline \multirow{8}{*}{$\begin{array}{l}\text { Adults }(\geq 18 \\
\text { years) } \\
(\mathrm{N}=1063)\end{array}$} & Total & & 440 & 41.4 \\
\hline & Sex & Male $(n=711)$ & 276 & $38.8^{*}$ \\
\hline & & Female $(n=352)$ & 164 & $46.6^{\star}$ \\
\hline & Age & $18-29(n=468)$ & 127 & $27.1 \dagger$ \\
\hline & & $30-39(n=318)$ & 140 & $44.0 †$ \\
\hline & & $40-49(n=158)$ & 82 & $51.9 \dagger$ \\
\hline & & 50-59 (n=78) & 56 & $71.8 \dagger$ \\
\hline & & $\geq 60$ years $(n=41)$ & 35 & $85.4 \dagger$ \\
\hline \multirow{7}{*}{$\begin{array}{l}\text { Children } \\
(\leq 17 \text { years }) \\
(\mathrm{N}=578)\end{array}$} & Total & & 107 & 18.5 \\
\hline & Sex & Boys $(n=313)$ & 47 & $15.0^{*}$ \\
\hline & & Girls ( $n=265)$ & 60 & $22.6^{\star}$ \\
\hline & Age & $0-4(n=171)$ & 57 & 33.3† \\
\hline & & 5-9 $(n=170)$ & 21 & $12.4 †$ \\
\hline & & $10-13(n=115)$ & 12 & $10.4 \dagger$ \\
\hline & & $14-17(n=122)$ & 17 & $13.9 \dagger$ \\
\hline
\end{tabular}

${ }^{*}$ Difference is significant at the 0.05 level.

†Difference is significant at the 0.001 level.

are not publicly available, and they were accessed on a written request to the Robert Koch Institute. The survey was conducted in Arabic which is the official language in Syria. Arabic literacy among Syrian nationals is high $(86.4 \%) .{ }^{21}$ Details about translating the questionnaire in this study are described in Aljadeeah et al. ${ }^{11}$ Participants were invited to bring to the interview the original packages, package inserts and patient information leaflets of all the medicines they had used in the previous 7 days.

To collect data on medicine use, a researcher asked each participant the following question: 'Did you use medicines or dietary supplements such as vitamins or minerals during the last seven days?' The question was repeated until the participants did not mention any additional products. Dietary supplements were defined as products that contain a dietary ingredient, for example vitamins, minerals and amino acids. ${ }^{22}$ For each medicine a respondent mentioned using, we recorded the brand name, the International Non-proprietary Name, pharmaceutical dosage form (tablets, syrup, etc), the number of daily doses, intake duration, the reason for taking the medicine, the administration route and how it was obtained (options included: (1) prescribed by a physician; (2) purchased without a prescription; (3) family medicine cabinet (prescribed by a physician to someone other than the person taking it); (4) family medicine cabinet (medicine was purchased without a prescription) or (5) any other source). A follow-up interview to gather missing information was arranged in cases when the participant did not bring all information for the medicines used in the past 7 days. The rest of the questionnaire, which included questions concerning sociodemographic characteristics, was selfadministered. The questionnaire administered in digital form on tablet computers using the online survey tool Qualtrics. ${ }^{23}$ For children who were younger than 14 years old, the questions were answered by parents. More information regarding the questionnaire and data collection can be found in Aljadeeah et al. ${ }^{11}$ We could not perform a power calculation to determine the sample size for this study because no adequate data that reported the use of medicines among AS\&Rs in Germany were available. We aimed for a relatively large sample size (1500 individuals). This was a pragmatic decision based on discussions with a biostatistician.

\section{Variables}

The 7-day prevalence was calculated as the proportion of AS\&Rs who has used at least one medicine in the 7 days preceding data collection. Other variables of interest were respondents' age and sex, the self-reported conditions or diseases that led to using medicines, the selfreported presence of chronic diseases and the use of prescribed medicines and self-medication. We differentiated between prescribed and self-medication on the basis of the answers to the question regarding the source of each recorded medicines (prescribed vs any other means, such as over-the-counter (OTC) purchase, provided by family members or friends, or other sources).

\section{Data analysis}

We stratified the sample into adults and children (the latter group included all participants younger than 18 years of age). We used the WHO's Anatomical Therapeutic Chemical (ATC) Classification system (2020 version) to classify the medicines reported in this study. ${ }^{24}$ Medicine consumption per therapeutic group is expressed in two forms: as a 7-day prevalence in adults and children and by the total number of doses for each medicine. From a drug utilisation research perspective, it is important to consider both the prevalence of medicine use and the number of doses, as the high number or frequency of medication doses is associated with medication burden among patients. ${ }^{25}$ The relative use of medicines is presented by stratifying the total amount of medicines used by the sex and age of the participants and by whether the medicines were prescribed or not. In addition, we report the number of defined daily doses (DDDs) for each medicine. DDD is defined as: 'the assumed average maintenance dose per day for a drug used for its main indication in adults. ${ }^{, 24}$ DDDs were calculated based on medicine use in adults. ${ }^{24}{ }^{26}$ The number of packages was used as a measurement unit for medicine consumption among children and teenagers, as DDD is not an appropriate measure for those age groups. ${ }^{27} 28$ 


\section{Statistical analysis}

We used Pearson's $\chi^{2}$ test to examine the differences between sex and age groups in the 7-day prevalence of using at least one medicine and in using prescribed medicines and self-medication. We also used Pearson's $\chi^{2}$ test to compare the proportions of adult participants who selfreported having chronic diseases in various sex and age groups. A $p<0.05$ was considered indicative of statistical significance. All statistical assessments were performed using IBM SPSS Statistics V.25 (IBM).

\section{Patient and public involvement}

As previously reported by Aljadeeah et $a l^{11}$ to address challenges of conducting research with AS\&R populations, and to enhance our understanding of the subject matter, we involved Syrian activists and other prominent members of the NRW Syrian community throughout the planning, execution and analysis of the study. Their support was particularly important in the recruitment of study participants. They also provided feedback on the findings and recommendations arising from the research.

\section{RESULTS}

\section{Prevalence of medicine use in the study population}

Of the 1641 Syrian AS\&Rs included in the analysis, 1063 were adults and 578 were children ( $\leq 17$ years). Males comprised $62.4 \%$ of the sample. The majority of participants lived in private housing $(78.6 \%)$, while $20.5 \%$ lived in RSACs. The average length of stay in Germany was 44.0 months. About $98 \%$ of the participants had health insurance. Information about other sociodemographic characteristics of the participants (health insurance status, employment status, education and income) can be found in online supplemental table 1. Among adult participants, the 7-day prevalence of using at least one medicine was $41.4 \%$. A total of 6466 doses of 951 medicines had been taken in the 7 days preceding the data collection (see table 1). The prevalence of medicine use was higher among females (46.6\%) than males (38.8\%). An increase in the prevalence of medicine use was observed with increasing age: the lowest prevalence was among adult participants between 18 and 29 years $(27.1 \%)$, and the highest was among those $\geq 60$ years $(85.4 \%)$.

Among the children, the prevalence of using at least one medicine was $18.5 \%$ and, in total, 738 doses of 135 medicines had been taken in the 7 days preceding data collection. The 7-day prevalence of medicine use was higher among girls (22.6\%) compared with the boys $(15.0 \%)$ (table 1). Unlike the adults, the youngest group of children (0-4 years) had the highest prevalence of medicine use.

\section{Conditions that led to using medications}

Among adult AS\&Rs, headache was the most commonly reported reason for taking medicines $(8.4 \%)$, followed by hypertension (6.7\%) (table 2 shows the 10 most common

\begin{tabular}{|c|c|c|c|c|}
\hline $\begin{array}{l}\text { Conditions that led to } \\
\text { medicines use }\end{array}$ & $\begin{array}{l}\text { No of participants who } \\
\text { had this condition }\end{array}$ & $\begin{array}{l}\text { Prevalence } \\
(\%)\end{array}$ & $\begin{array}{l}\text { No of } \\
\text { doses }\end{array}$ & $\begin{array}{l}\text { No of different medicines } \\
\text { taken for this condition }\end{array}$ \\
\hline Hypertension & 71 & 6.7 & 954 & 26 \\
\hline Gastric pain & 49 & 4.6 & 426 & 6 \\
\hline Spinal pain & 38 & 3.6 & 276 & 10 \\
\hline Stroke prevention & 30 & 2.8 & 203 & 3 \\
\hline Hypothyroidism & 30 & 2.8 & 215 & 3 \\
\hline Influenza & 26 & 2.5 & 175 & 12 \\
\hline Influenza & 18 & 3.1 & 89 & 3 \\
\hline Dietary supplement & 13 & 2.3 & 85 & 3 \\
\hline Common cold & 10 & 1.7 & 68 & 4 \\
\hline Epilepsy & 3 & 0.5 & 14 & 1 \\
\hline Otitis media & 3 & 0.5 & 33 & 4 \\
\hline Asthma & 3 & 0.5 & 21 & 3 \\
\hline Headache & 2 & 0.4 & 7 & 3 \\
\hline Painful menstruation & 2 & 0.4 & 6 & 1 \\
\hline
\end{tabular}




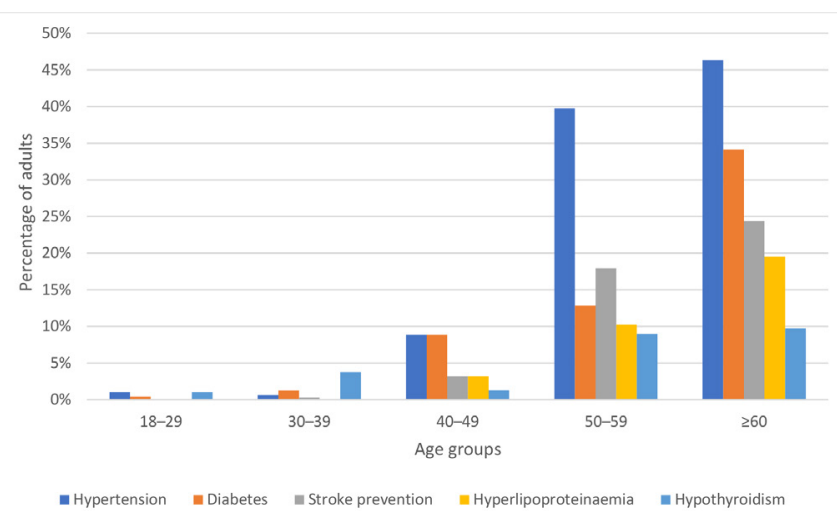

Figure 1 The five most common chronic conditions that led to medicine use among adult participants by age.

causes). The greatest number of individual doses of medicine were for hypertension (954 doses) and diabetes (595 doses). Four of 10 most commonly reported reasons for medicines use were chronic conditions: hypertension, diabetes, stroke prevention and hypothyroidism. In total, $13.7 \%$ of the adults stated that they had one or more chronic disease for which they took medicine. More females $(17.9 \%)$ than males $(11.7 \%)$ reported having chronic diseases for which they took medicines (online supplemental figure 1) and this difference was statistically significant $(p=0.006)$. The proportion of participants who reported having chronic diseases increased with age (figure 1) and the differences between age groups were statistically significant $(p<0.001)$. Among the 10 most common conditions that led to medicine use, one was infectious (influenza). None were mental disorders; 17 adults $(1.6 \%)$ reported taking 181 doses of 21 psychotropic medicines for mental diseases.

Among children, fever (5.5\%) and cough (4.0\%) were the most common conditions that led to medicine use (table 2). We found that $1.6 \%$ of the children had taken medicine for chronic diseases, and 2 of top 10 causes for medicine use were chronic diseases (epilepsy and

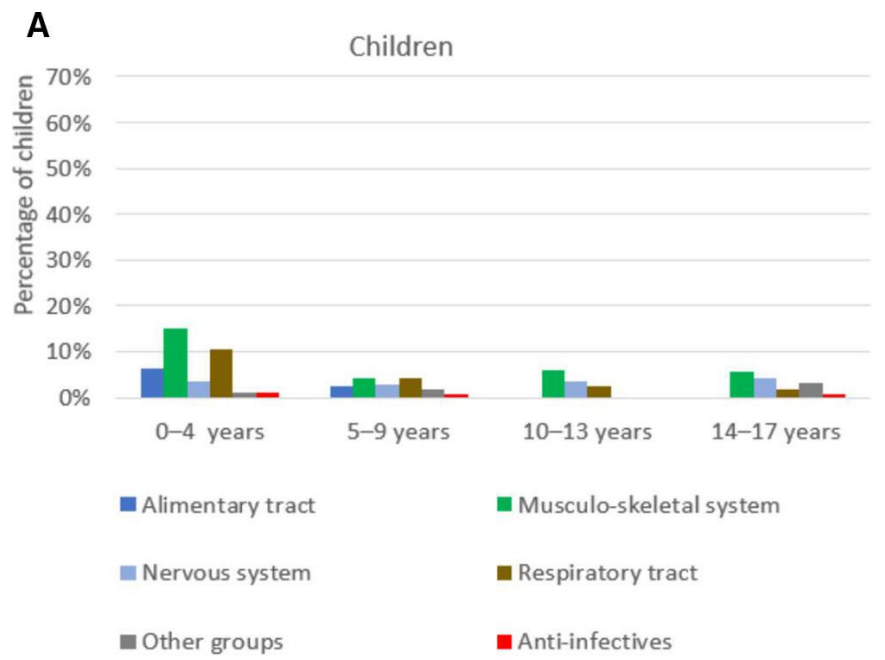

asthma). Of the remaining eight most frequent causes of use of medicines, four were infectious diseases (influenza, cough, common cold and otitis media). None of the children took medicine to treat mental diseases.

\section{Patterns of medicine use by ATC group}

Among adults, the highest prevalence of medicine use $(14.6 \%)$ was for medicines for the alimentary tract and metabolism (ATC code A); this was followed by medicines of the musculoskeletal system (M) (13.4\%), the nervous system (N) (12.4\%) and the cardiovascular system (C) $(8.0 \%)$. The prevalence of medicine use in these groups varied between males and females. Among males, medicine use from the M group (13.8\%) was highest compared with the other ATC groups, followed by group A medicines $(13.5 \%)$. Among females, the prevalence of medicine use in group A was the highest (16.8\%), followed by group $\mathrm{N}$ medicines (12.8\%) (online supplemental figure 2).

The prevalence of medicine use by ATC group also varied between the different age groups. Among participants in the 18-29 and 30-39 age groups, the prevalence of group M medicines use was highest $(7.5 \%$ and $15.7 \%$, respectively). In the $40-49$ and $\geq 60$ years age groups, use of group A medicines had the highest prevalence $(22.8 \%$ and $63.4 \%$, respectively). In the 50-59 age group, group $\mathrm{C}$ medicines had the highest prevalence $(42.3 \%$ ) (figure 2 ).

Among the children, the prevalence of group $\mathrm{M}$ medicine use was the highest $(8.1 \%)$, followed by those in the respiratory system (ATC code R) $(4.7 \%)$, and the medicines of groups $\mathrm{N}$ and $\mathrm{A}(3.5 \%$ and $2.6 \%$, respectively). Among both boys and girls, the prevalence of group $\mathrm{M}$ medicine use was highest $(6.07 \%$ and $10.6 \%$, respectively) (online supplemental figure 2). The prevalence of use of group $\mathrm{M}$ medicines was the highest among all age groups of the children (figure 2).

The most frequently used medicine among adults was ibuprofen, which was used by $10.4 \%$ of adults, followed by paracetamol $(6.8 \%)$ and omeprazole $(3.1 \%)$. Ibuprofen

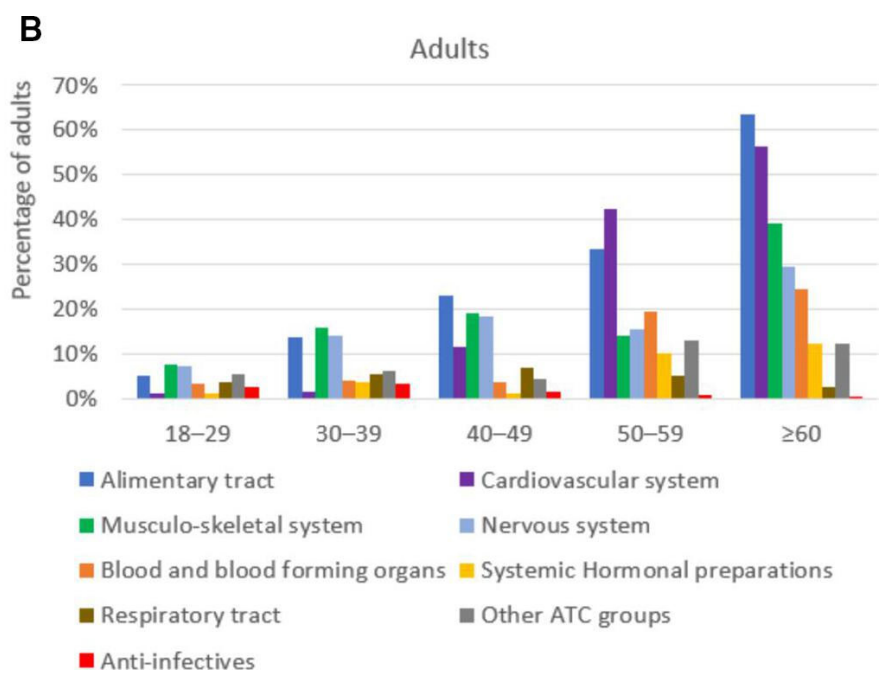

Figure 2 Prevalence of use of medicines from the main ATC groups among adult and child study participants, by age group. ATC, anatomical therapeutic chemical. 
Table 3 Prescribed or self-medication use among adult and child participants, by sex and age

\begin{tabular}{|c|c|c|c|c|c|c|c|c|}
\hline & & & \multicolumn{2}{|c|}{ Prescribed medication } & \multicolumn{2}{|c|}{ Self-medication } & \multicolumn{2}{|c|}{ Both } \\
\hline & & & $\mathbf{n}$ & $\%$ & $\mathbf{n}$ & $\%$ & $\mathbf{n}$ & $\%$ \\
\hline Total & & & 333 & 20.3 & 158 & 9.6 & 55 & 3.4 \\
\hline \multirow{6}{*}{$\begin{array}{l}\text { Adults } \\
(18<=)\end{array}$} & \multirow[t]{2}{*}{ Sex } & Male & 175 & $24.6^{\star}$ & 76 & 10.7 & 25 & 3.5 \\
\hline & & Female & 102 & $29.0^{\star}$ & 32 & 9.1 & 30 & 8.5 \\
\hline & \multirow{4}{*}{ Age } & $30-39$ & 71 & 22.3† & 48 & $15.1^{\star}$ & 21 & 6.6 \\
\hline & & $40-49$ & 58 & $36.7 \dagger$ & 12 & $7.6^{\star}$ & 12 & 7.6 \\
\hline & & $50-59$ & 41 & $52.6 \dagger$ & 5 & $6.4^{*}$ & 10 & 12.8 \\
\hline & & $\geq 60$ & 31 & 75.6† & 1 & $2.4^{*}$ & 3 & 7.3 \\
\hline \multirow{5}{*}{$\begin{array}{l}\text { Children } \\
(<18)\end{array}$} & Total & & 56 & 9.7 & 50 & 8.7 & 1 & 0.1 \\
\hline & \multirow[t]{4}{*}{ Age } & $0-4$ & 29 & 17.0 & 27 & 15.8 & 1 & 0.6 \\
\hline & & $5-9$ & 14 & 8.2 & 7 & 4.1 & 0 & 0 \\
\hline & & $10-13$ & 6 & 5.2 & 6 & 5.2 & 0 & 0 \\
\hline & & $14-17$ & 7 & 5.7 & 10 & 8.2 & 0 & 0 \\
\hline
\end{tabular}

*Difference is significant at the 0.01 level.

†Difference is significant at the 0.001 level.

was also the medication with the highest number of doses used $(9.7 \%)$, followed by metformin (for diabetes) $(5.1 \%)$ (online supplemental table 2). Among the children, ibuprofen was also the most used medication $(8.1 \%)$, followed by hederae helicis folium (the active ingredient in expectorant preparations) $(3.1 \%)$ and paracetamol (2.3\%) (online supplemental table 2 ).

\section{Prescribed medication, self-medication and sharing of medications}

Of the 1086 medicines recorded in the study, $824(75.9 \%)$ were prescribed by physicians and 262 medicines $(24.1 \%)$ were used by self-medication. Of the 951 medicines used by the adults, $78.7 \%$ were prescribed by physicians and $21.3 \%$ were used by self-medication. Fewer adult males used prescribed medicines compared with females ( $24.6 \%$ vs $29.0 \%$ respectively, $\mathrm{p}=0.002)$. The prevalence of self-medication was only slightly higher among males than females $(10.7 \%$ and $9.1 \%$, respectively, $\mathrm{p}=0.147)$ (table 3).

The prevalence of prescription medication use increased with age. Self-medication varied among age groups, with the highest prevalence among participants in the $30-39$ age group $(15.1 \%)$ and the lowest in those $\geq 60$ years $(2.4 \%)$ (table 3$)$.

Among the children, $56.3 \%$ of the 135 medicines used were prescribed by physicians and $43.7 \%$ were used by self-medication. The prevalence of using medicines by self-medication was higher among girls than boys $(11.3 \%$ and $8.3 \%$, respectively; $p=0.051$ ) (table 3 ). The prevalence of use of prescribed medicines was higher among the 0-4 age group (17.0\%) when compared with the other childhood age groups. The prevalence of using medicines by self-medication was also higher among the $0-4$ age group $(15.8 \%)$ when compared with the other childhood age groups $(\mathrm{p}=0.14)$ (table 3$)$.

Among adult participants, 37 adults (3.5\%) shared 37 medicines with other people. Of the 37 medicines, 16 were OTC medicines. The remaining 21 medicines were prescription-only medicines. Fourteen adults (1.3\%) used medicines that had been imported and not purchased in Germany. Among the children, 32 (5.5\%) shared 32 OTC medicines with other people (online supplemental table 3 ).

\section{DISCUSSION}

In Germany, there is a lack of routine reporting on the health status and quality of medical care, including medication use, among AS\&Rs. Empirical studies are needed to provide evidence to improve policy and clinical practice with this population. ${ }^{9}$ To our knowledge, this is the first study to report comprehensively on medicine use and indications among a group of AS\&Rs in Germany.

This study contributes new insights about medication use among Syrian AS\&Rs. First, the use of medicines for NCDs was relatively common among adults, with hypertension being the second-most common condition that led to their use of medicines. Treating two chronic diseases, hypertension and diabetes, led to using the highest number of doses of medicine in the study period. Second, although acute conditions, such as fever and cough, were 
the most common reasons for children's medicines use, overall we found a low prevalence of use of medicines, including antibiotics, for infectious diseases. Third, the prevalence of psychotropic medicine use was also low in our study. These and other findings have meaningful implications for both policy and clinical medical practice.

Among adult participants, the 7-day prevalence of using at least one medicine was $41.4 \%$. The 2008-2011 DEGS study described medicines use in a representative sample of the German adult population and found that the 7-day prevalence for using at least one medicine reached $74.4 \% .{ }^{17}$ This is not unexpected because the Syrian AS\&R study population was overall younger than the DEGS study population. Another possible reason for the different rates of medicine use is related to lower utilisation of healthcare services among AS\&Rs compared with German citizens with statutory health insurance. Barriers that limit AS\&Rs' access to healthcare services, including language barriers and limited knowledge about the health system in Germany, are some of the reasons that may explain the results; this area should be further explored. ${ }^{15}$ Similar to our study, the DEGS and KiGGS studies reported medicines use in the last 7 days prior to data collection and included both prescribed medicines and self-medication in the general population. However, comparing the results of our study with the results of the DEGS and KiGGS should be considered with caution. The DEGS and KiGGS studies comprised the entire country whereas our study took place in one state (Land). In addition, our survey was conducted in 2019, while the DEGS and KiGGS surveys were conducted in 2008-2011 and 2014-2017, respectively.

In our study, the prevalence of medicine use was higher among females, which could be explained by the higher proportion of female participants who self-reported having one or more chronic disease. The prevalence of medicine use increased with age, which is also likely related to the higher prevalence of chronic conditions in older age groups. The DEGS study also found that prevalence was higher among females and increased with age. Medicine use among the 18-29years old in our study was also considerably lower than in the DEGS study (27.1\% vs $61.2 \%$, respectively). However, the differences between German natives and AS\&Rs steadily decreased with increasing participant age, with little difference in the over 60 age groups.

Among the children in our study, we found that the 7-day prevalence of using at least one medicine was $18.5 \%$. Prevalence was higher among girls; children in the $0-4$ age group had the highest prevalence of medicine use, followed by those in the 14-17 age group. For comparison with the general population, the 2014-2017 KiGGS study on medicine use in a representative sample of German children from 3 to 17 years old reported a $36.4 \%$ prevalence of use of at least one medicine in the previous 7 days. The prevalence in the KiGGs study was similarly higher among girls. ${ }^{27}$ By age, the highest prevalence occurred in the 14-17 age group. However, the
KiGGS study did not include children younger than 3 years of age.

Hypertension was the second-most common condition that led to medicine use among adults, and 4 of the 15 most commonly used medicines among adults were for the treatment of hypertension (namely, amlodipine, hydrochlorothiazide, candesartan and ramipril). Hypertension and diabetes were the two diseases that led to the highest number of medication doses. Our results are consistent with studies that have reported high prevalence of both hypertension and diabetes among Syrian refugees in Jordan, Lebanon, Turkey and other countries in Europe. ${ }^{310}{ }^{29}$ NCDs were also the diseases that most commonly led to medicine use among the adult German population. ${ }^{30}$

Our study found a low prevalence of medicine use for the treatment of infectious diseases in adults. Influenza was the only infectious disease among the ten most common causes for medication use, and amoxicillin was the only antibiotic among the 15 most commonly used medicines by adults. Amoxicillin was also found to be the most commonly prescribed antibiotic for a group of asylum seekers in the city of Erlangen, ${ }^{14}$ and is the most commonly prescribed antibiotic for Germans with statutory health insurance. ${ }^{31}$ The low prevalence of medicine use to treat infectious diseases is consistent with several other studies on the prevalence of diseases among Syrian refugees in Germany and other countries. One study reported a very low prevalence of tuberculosis among Syrian AS\&Rs in Germany compared with AS\&Rs from other nationalities. ${ }^{32} 33$ Another study that investigated the health status of AS\&Rs in the state of Bavaria showed a low prevalence of infectious diseases (4.8\%) among Syrians. ${ }^{34}$ In 2013, an increase in the incidence of 13 infectious diseases was expected in Turkey following the start of the conflict in Syria. However, since the influx of 3.5 million Syrian refugees to Turkey, there have been increases in cases of leishmaniasis and measles, but no significant increases in other infectious diseases have been detected. ${ }^{35}$ A study from Australia has also reported a low prevalence of infectious diseases among Syrian AS\&Rs. ${ }^{36}$ Given the apparently low prevalence of infectious diseases among Syrian AS\&Rs, it is not surprising that our study found low rates of use of medicines for these diseases.

Our results on the frequency of prescription medicine use $(78.7 \%)$ and self-medication $(21.4 \%)$ are similar to the DEGS study, in which $71.8 \%$ of the medicines used over a 7-day period were prescribed by a physician and $27.7 \%$ were used by self-medication. ${ }^{17}$ Among children in our study, $56.3 \%$ of medicines used were prescribed by physicians, and $43.7 \%$ were self-medication. Results from the KiGGs study also showed that children used more prescription medicines than self-medication. ${ }^{30}$ A similar outcome was reported in a study that focused on medicine use among child refugees in England. ${ }^{37}$

There was little antibiotic use reported in our study. This finding contrasts with studies by Kahl and Kühlein 
who reported a high proportion of antibiotic prescriptions for asylum seekers in Erlangen. However, the authors did not provide either the reasons for prescribing antibiotics or the nationality or sex of their study population. ${ }^{145}$ Factors such as country of origin have considerable effects on refugees' health, and this factor may account for our divergent findings. ${ }^{29}$ Syrian AS\&Rs present with different demographic profiles and disease burden than, for instance, AS\&Rs from some African countries where a disease such as cholera would be more prevalent. ${ }^{10}$ Another factor that could explain differences between our results and those of Kahl and Kühlein may be due to their sample, which was limited to newly arrived asylum seekers. In Kahl Kühlein, the average period of stay in the reception centre was 46.9 days while the average stay of our participants in Germany was 44.0 months. The duration of stay in a host country can play a role in the health status of AS\&Rs-over a longer period of stay, AS\&R health profile tends to converge with that of the host country's population. ${ }^{29} 32$

Housing status is an important social determinant of health. ${ }^{38}$ Studies that have previously reported on the health status and utilisation of healthcare services among AS\&Rs in Germany were based on data collected in RSACs. ${ }^{9} 14-16$ This could be connected to difficulties in collecting reliable data on the health status of AS\&Rs living in private housing. ${ }^{39}$ Living in RSACs is related to higher levels of distress. ${ }^{40}$ While other studies have provided valuable information about the health status and the use of medicines among those asylum seekers who live in RSACs, their findings cannot be generalised to the majority of the AS\&R population in Germany. By 2018, approximately 75\% of AS\&Rs in Germany lived in private apartments. ${ }^{41}$ For this study, we intentionally sought to reach AS\&Rs who lived in private housing. As $78.6 \%$ of our participants lived in private housing, we believe that our study group was more representative of the Syrian AS\&R population than other studies, which were limited to AS\&Rs living in RSACs.

Prior studies have described a high prevalence of mental disorders, such as post-traumatic stress disorder, among different groups of AS\&Rs in Germany. ${ }^{942}$ However, the prevalence of psychotropic medicine use was low in our study. Kahl and Frewer suggested that the prescription rates for psychotropic drugs were also under-represented in their study compared with the higher prescription rates of these medicines among the German population. ${ }^{15}$ Of course, some psychotherapeutic interventions do not involve pharmacotherapy. However, access to these therapies among AS\&Rs is clearly also limited due to language barriers. Pharmacotherapy to manage mental disorders remains a feasible choice for AS\&Rs in Germany. ${ }^{15}$ Reasons for the low prevalence of psychotropic medicines use found in our study could be related to various barriers to accessing mental health services among AS\&Rs. These include language barriers, lack of information about the existence of mental health services, and stigma around seeking mental health services. ${ }^{43}$ The low prevalence of psychotropic medicine in our study should be further examined to determine whether Syrian AS\&Rs have been neglected by mental health services. ${ }^{15}$

The management of NCDs such as hypertension and diabetes require adherence to continuous pharmacotherapy and frequent laboratory tests, which poses a challenge for AS\&Rs in many countries. ${ }^{5-8}$ Currently, infectious diseases received the most attention of the policy and clinical practice related to AS\&Rs compared with the management of NCDs. ${ }^{29}$ In Germany, asylum seekers of all nationalities are obliged to participate in chest X-ray examinations to screen signs of potentially infectious pulmonary tuberculosis (except for pregnant women and children younger than 15 years of age). ${ }^{33}$ Policies in Germany should account for the different regions where AS\&Rs come from and the burden of diseases that could vary between these regions. Since 2015, the chest X-ray screening for tuberculosis for Syrian asylum seekers in the Netherlands was suspended as the tuberculosis incidence in Syria was low $(<50$ cases per 100 000 people). Limiting this screening to asylum seekers from high-incidence countries could improve costeffectiveness. ${ }^{44}$ The resources and efforts paid to X-ray screening for tuberculosis among Syrian AS\&Rs can be invested instead in the prevention and management of NCDs. The high prevalence of medicines use for hypertension and diabetes in our study raises the question of whether enough attention has been paid to develop policies and clinical practices to ensure NCDs care in the Syrian AS\&R population. This outcome of our study also indicates the need to rethink the healthcare policies for AS\&Rs populations in a decade when the largest displacement emergency in the world has happened in Syria, a country with a high burden of NCDs. ${ }^{10}$ Additional efforts are needed to raise awareness about the prevention and management of NCDs among AS\&Rs.

\section{Strengths and limitations}

The complexity of AS\&R health statuses makes it difficult to generalise research findings from one group to the wider populations of AS\&Rs. ${ }^{29}$ To increase generalisability of our study, we employed a combination of sampling methods and took into account key demographic variables (age and sex) during the design of the sample. Furthermore, study recruitment was not limited to RSACs.

This study had a number of strengths. By collecting primary data, we were able to comprehensively report on the use of medicines among Syrian AS\&Rs, including prescription and self-medication. We were also able to record the diseases and conditions that led to using medicines. Since we relied on self-reported medicine use, we asked participants to bring to the interview original packages, package inserts and patient leaflets for their medicines to minimise recall bias. However, the possibility of recall bias cannot be excluded. ${ }^{45}$ We validated participants' answers by reviewing the package information. We did not use prescriptions or claims data-as many 
other studies have-to avoid focusing only on medicines that were prescribed or covered by health insurance. By using self-reporting, we covered both prescription and self-medication, and determined actual consumption. ${ }^{17}$ Another strength of our study was the involvement of our target population in several stages of the research design and implementation. Participation of AS\&R community members ensured that the study instruments were well adapted to the culture of the target population.

Our study was restricted to medicines used over the previous 7 days in order to maximise the participants' recall accuracy. However, using a limited time frame could have led to underestimating the use of medicines. For example, there may be medications that are often taken by participants, but which had been interrupted during this time frame. ${ }^{17}$ Severely ill AS\&Rs who might have been hospitalised could not participate in our survey. This might have led to the underestimation of medicines use in our study population. Our study was limited to one state (NRW), while the DEGS and KiGGS studies comprised the entire country. In Germany, there are variations in the prevalence of medicine use between the different states. ${ }^{17}$ Another limitation of this study is related to the seasonal variation of medicine use. The study lasted for 6 months (July-December) capturing part of the seasonal variation expected annually. Future studies should consider annual seasonal variation. Finally, the number of participants in the $\geq 60$ age group, which had been estimated based on census data, was relatively small. To achieve a better understanding of medicine use among this age group, future studies should focus on this age group.

\section{CONCLUSION}

Studies have documented an epidemiological shift, from infectious diseases to NCDs, among AS\&Rs as among general populations in many countries. However, previous research with AS\&Rs populations in Germany has focused on mental disorders and infectious diseases. Studies on the use of medicines for NCDs and other diseases are still scarce. This study provided a detailed look at the use of medicines among a large sample of AS\&Rs living in shortterm and long-term accommodations and found that adult AS\&Rs commonly used medicines for the treatment or management of NCDs. We encourage future studies to pay more attention to detection, treatment and management of NCDs among AS\&Rs in Germany, including those who live in private housing.

This and other similar studies can inform and improve national and international policies and plans to prevent, control and reduce the burden of NCDs among AS\&R populations. We further strongly encourage the involvement of AS\&Rs in health research focused on their communities. Through regular interactions with AS\&Rs communities at all stages of research projects, researchers can improve the quality, value and relevance of their research.
Twitter Saleh Aljadeeah @SalehAljadeeah

Acknowledgements The authors thank every asylum seeker and refugee who helped and participated in this study. We thank every researcher who helped in validating the questionnaire for this study. We thank the following authorities and organisations for establishing the access to the facilities where data for this study were collected: The German Red Cross, the Social Security office of the municipality of Colone, The Muslim Women's Meeting and Training Centre in Cologne, Social Service of Catholic Men in Cologne and The Statistics Office of NRW (Information und Technik Nordrhein-Westfalen (IT.NRW) Statistisches Landesam).

Contributors SA is responsible for the study conceptualisation, design, data collection, data analysis and drafting of the manuscript. VW contributed to the study conceptualisation, design, data analysis, manuscript review and editing and supervision. EN contributed to the study conceptualisation, design, manuscript review and editing and supervision. All authors read and approved the final manuscript.

Funding This work was supported by a PhD fellowship from the Konrad Adenauer Foundation. (Grant number: 007346). This publication was funded by the German Research Foundation (DFG) and the University of Bayreuth in the funding programme Open Access Publishing.

Disclaimer The funder had no role in the design and conduct of the study, the analysis and interpretation of the data, or the preparation, review and approval of the manuscript.

\section{Competing interests None declared.}

Patient consent for publication Not applicable.

Ethics approval The study was approved by the ethics committee of the University of Bayreuth (protocol code 0 1305/1-GB GB. Date of approval: 21 May 2019).

Provenance and peer review Not commissioned; externally peer reviewed.

Data availability statement No data are available.

Supplemental material This content has been supplied by the author(s). It has not been vetted by BMJ Publishing Group Limited (BMJ) and may not have been peer-reviewed. Any opinions or recommendations discussed are solely those of the author(s) and are not endorsed by BMJ. BMJ disclaims all liability and responsibility arising from any reliance placed on the content. Where the content includes any translated material, BMJ does not warrant the accuracy and reliability of the translations (including but not limited to local regulations, clinical guidelines, terminology, drug names and drug dosages), and is not responsible for any error and/or omissions arising from translation and adaptation or otherwise.

Open access This is an open access article distributed in accordance with the Creative Commons Attribution Non Commercial (CC BY-NC 4.0) license, which permits others to distribute, remix, adapt, build upon this work non-commercially, and license their derivative works on different terms, provided the original work is properly cited, appropriate credit is given, any changes made indicated, and the use is non-commercial. See: http://creativecommons.org/licenses/by-nc/4.0/.

\section{ORCID iD}

Saleh Aljadeeah http://orcid.org/0000-0003-4035-4121

\section{REFERENCES}

1 Spiegel PB, Checchi F, Colombo S, et al. Health-care needs of people affected by conflict: future trends and changing frameworks. Lancet 2010;375:341-5.

2 Amara AH, Aljunid SM. Noncommunicable diseases among urban refugees and asylum-seekers in developing countries: a neglected health care need. Global Health 2014;10:24.

3 El Arnaout N, Rutherford S, Zreik T, et al. Assessment of the health needs of Syrian refugees in Lebanon and Syria's neighboring countries. Confl Health 2019;13:31.

4 World Health organization. Global health estimates, 2020. Available: https://www.who.int/data/global-health-estimates [Accessed 15 Jan 2021].

5 Hogerzeil HV, Liberman J, Wirtz VJ, et al. Promotion of access to essential medicines for non-communicable diseases: practical implications of the UN political Declaration. Lancet 2013;381:680-9.

6 Moucheraud C, Lenz C, Latkovic M, et al. The costs of diabetes treatment in low- and middle-income countries: a systematic review. BMJ Glob Health 2019;4:e001258.

7 Demaio A, Jamieson J, Horn R, et al. Non-Communicable diseases in emergencies: a call to action. PLoS Curr 2013;5. doi:10.1371/ 
currents.dis.53e08b951d59ff913ab8b9bb51c4d0de. [Epub ahead of print: 06 Sep 2013].

8 Kayali M, Moussally K, Lakis C, et al. Treating Syrian refugees with diabetes and hypertension in Shatila refugee camp, Lebanon: Médecins Sans Frontières model of care and treatment outcomes. Confl Health 2019;13:12.

9 Bozorgmehr K, Mohsenpour A, Saure D, et al. Systematische Übersicht und „Mapping“ empirischer Studien des Gesundheitszustands und der medizinischen Versorgung von Flüchtlingen und Asylsuchenden in Deutschland (1990-2014). Bundesgesundheitsblatt Gesundheitsforschung Gesundheitsschutz 2016:59:599-620.

10 Naja F, Shatila H, El Koussa M, et al. Burden of non-communicable diseases among Syrian refugees: a scoping review. BMC Public Health 2019:19:637.

11 Aljadeeah S, Wirtz VJ, Nagel E. Barriers to accessing medicines among Syrian asylum seekers and refugees in a German federal state. Int J Environ Res Public Health 2021:18:519.

12 Royal Pharmaceutical Society. Medicines optimisation: medicines optimisation: helping patients to make the most of medicines: good practice guidance for healthcare professionals in England, 2013.

13 Klein J, von dem Knesebeck O, dem KOvon. Inequalities in health care utilization among migrants and non-migrants in Germany: a systematic review. Int J Equity Health 2018;17:160.

14 Kahl F, Kühlein T. Differences between the antibiotic prescribing pattern of newly arrived refugees in Germany and the German population. Confl Health 2018;12:3.

15 Kahl F, Frewer A. Medizinische Versorgung von neu angekommenen Asylsuchenden in Erlangen: Eine studie zum Medikamenteneinsatz mit besonderem Blick auf Psychopharmaka. Psychother Psychosom Med Psychol 2017:67:119-25.

16 Niedermaier A, Freiberg A, Tiller D, et al. Outpatient health care utilization and health expenditures of asylum seekers in Halle (Saale), Germany - an analysis of claims data. BMC Health Serv Res 2020;20:961.

17 Knopf H, Grams D. Arzneimittelanwendung von Erwachsenen in Deutschland Ergebnisse der Studie zur Gesundheit Erwachsener in Deutschland (DEGS1). Bundesgesundheitsblatt Gesundheitsforschung Gesundheitsschutz 2013;56:868-77.

18 Enticott JC, Shawyer F, Vasi S, et al. A systematic review of studies with a representative sample of refugees and asylum seekers living in the community for participation in mental health research. BMC Med Res Methodol 2017;17:37.

19 Robert Koch Institute. Studie zur Gesundheit Erwachsener in Deutschland (DEGS).. Available: https://www.degs-studie.de/ deutsch/home.html [Accessed 10 Jan 2021].

20 Robert Koch Institute. Studie zur Gesundheit von Kindern und Jugendlichen in Deutschland (KIGGS). Available: https://www.kiggsstudie.de/deutsch/home.html [Accessed 10 Jan 2021].

21 Al Hassan M, Bengtsson S, Kohlenberger J. Understanding the Syrian educational system in a context of crisis, 2016. Available: https://www.econstor.eu/bitstream/10419/156317/1/875728065.pdf [Accessed 04 Sep 2021].

22 U.S. Food \& Drug Adminstration. FDA 101: dietary supplements. Available: https://www.fda.gov/consumers/consumer-updates/fda101-dietary-supplements [Accessed 02 Apr 2021].

23 Provo, UT, USA. Qualtrics, 2020. Available: https://www.qualtrics. com [Accessed 15 Jan 2021].

24 WHO Collaborating Centre for Drug Statistics Methodology. ATC/ DDD Index 2020. Available: https://www.whocc.no/atc_ddd_index/ [Accessed 15 Feb 2021].

25 Keasley J, Oyebode O, Shantikumar S, et al. A systematic review of the burden of hypertension, access to services and patient views of hypertension in humanitarian crisis settings. BMJ Glob Health 2020;5:e002440.

26 World Health organization. Essential medicines and health products: more about DDDs. Available: https://www.who.int/medicines/ regulation/medicines-safety/toolkit_ddd_more/en/ [Accessed 15 Feb 2021].

27 Elseviers M, Stichele RV, Vlahovic-Palcevski V. Drug utilization research: methods and applications. Malden, MA: Wiley-Blackwell, 2016: 550-3

28 Clavenna A, Sequi M, Bortolotti A, et al. Determinants of the drug utilization profile in the paediatric population in Italy's Lombardy region. Br J Clin Pharmacol 2009;67:565-71.

29 World Health organization. Report on the health of refugees and migrants in the WHO European region: no PUBLIC health without refugee and migrant health, 2018. Available: https://apps.who.int/ iris/bitstream/handle/10665/311347/9789289053846-eng.pdf? sequence $=1$ \&isAllowed $=y \& u a=1$ [Accessed 10 Feb 2021]

30 Knopf HC. Arzneimittelanwendung im Kindes- und Erwachsenenalter in Deutschland - Ergebnisse der bundesweiten Interview- und Untersuchungssurveys. Public Health Forum 2017;25:201-5.

31 Grandt D, Lappe V, Schubert I. BARMER Arzneimittelreport 2020: Sektorenübergreifende Arzneimitteltherapie. 2020. 1st edn. Wuppertal: Barmer

32 Herzmann C, Golakov M, Malekzada F, et al. Radiological screening of refugees in Germany. Eur Respir J 2017;49. doi:10.1183/13993003.02487-2016. [Epub ahead of print: 2505 2017].

33 Tewes S, Hensen B, Jablonka A, et al. Tuberculosis screening during the 2015 European refugee crisis. BMC Public Health 2020;20:200.

34 Institut für Medizinmanagement und Gesundheitswissenschaften, Universität Bayreuth. Auswirkungen des Zustroms von Asylbewerbern auf Die Gesundheitliche Versorgung in Bayern. Available: https://www.lgl.bayern.de/gesundheit/gesundheitsverso rgung/doc/kurzbericht_auswirkungen_zustrom_asylbewerber_gv_by. pdf [Accessed 9 Feb 2021].

35 Ergönül Ö, Tülek N, Kayı l, et al. Profiling infectious diseases in Turkey after the influx of 3.5 million Syrian refugees. Clin Microbiol Infect 2020;26:307-12.

36 Maldari T, Elsley N, Rahim RA. The health status of newly arrived Syrian refugees at the refugee health service, South Australia, 2016. Aust J Gen Pract 2019;48:480-6.

37 Alkahtani S, Cherrill J, Millward C, et al. Access to medicines by child refugees in the East Midlands region of England: a cross-sectional study. BMJ Open 2014;4:e006421.

38 Ziersch A, Walsh M, Due C, et al. Exploring the relationship between housing and health for refugees and asylum seekers in South Australia: a qualitative study. Int J Environ Res Public Health 2017;14. doi:10.3390/ijerph14091036. [Epub ahead of print: 0809 2017].

39 UNHCR. Health access and utilization survey among Syrian refugees in Lebanon, 2017. Available: file:///C:/Users/asus/AppData/Local/ Temp/1513604936-1.pdf [Accessed 9 Feb 2021].

40 Walther L, Fuchs LM, Schupp J, et al. Living conditions and the mental health and well-being of refugees: evidence from a largescale German survey. J Immigr Minor Health 2020;22:903-13.

41 Tanis K. Entwicklungen in der Wohnsituation Geflüchteter. Ausgabe 05|2020 der Kurzanalysen des Forschungs-zentrums migration, integration und Asyl des Bundesamtes für migration und Flüchtlinge, 2020.

42 Lebano A, Hamed S, Bradby H, et al. Migrants' and refugees' health status and healthcare in Europe: a scoping literature review. BMC Public Health 2020;20:1039.

43 Renner A, Hoffmann R, Nagl M, et al. Syrian refugees in Germany: perspectives on mental health and coping strategies. $J$ Psychosom Res 2020;129:109906.

44 Akkerman OW, de Lange WCM, Schölvinck EH, et al. Implementing tuberculosis entry screening for asylum seekers: the Groningen experience. Eur Respir J 2016;48:261-4.

45 Sarganas G, Buttery AK, Zhuang W, et al. Prevalence, trends, patterns and associations of analgesic use in Germany. BMC Pharmacol Toxicol 2015;16:28. 